education? The first requirement is the political will to channel national resources from the military to social needs. African states are rarely threatened by the neighbouring countries, and yet their military expenditure has increased five-fold over the last couple of decades!

The three challenges Forje poses, namely needsoriented policy, cultural bias and environment suitable for creativity and innovation, will be successful only if science and technology move out of the ivory towers of academia and research institutes to the market area, where economics become the determining factor, and $S \& T$ activities are directed to meet the needs of the market. The link between S\&T policy, trade and economic policies, not forgetting sociocultural policies, cannot be over-emphasised.

\section{Reference}

1. John WForje, "Development and technology policy in a changing society: challenges for the African political structures" Science and Public Policy, 22(2), April 1995, pages 121-129.

\title{
Embedding integrated assessment models in social discourse
}

\author{
B Kasemir, C C Jaeger and G Dürrenberger
}

I N THEIR PAPER (Science and Public Policy, 22(4), August 1995, pages 218-230) Simon Shackley and Brian Wynne argue that with regard to climate-related research, criteria for good science are not being determined solely from within science. Rather, they emerge through a process of "mutual construction" with government policy institutions. In comments to this paper, Boehmer-Christiansen agrees with this claim but insists that even more institutions are involved than those considered by Shackley and Wynne, while van Asselt with Rotmans show how the idea of 'mutual construction' can inspire new modelling strategies (Science and Public Policy, 22(6), December 1995, pages 411-413, and 414-415).

Shackley and Wynne's analysis of the situation in climate research is very much to the point. But what are the implications of 'mutual construction' for the use of models, which are major products of climaterelated research? Shackley and Wynne draw the conclusion that:

"[if] science alone is unable to provide a sufficient basis for underpinning political commitment to policy actions, then a public discussion about the many other possible justifications for acting on the issue of climate change is imperative ..."

This could be taken to suggest not only that a public discussion about climate change is important, but that this discussion and scientific modelling efforts should

B Kasemir and G Durrenberger are at the Swiss Federal Institute for Environmental Science and Technology (EAWAG), Human Ecology Division, Ueberlandstr. 133,8600 Duebendorf, Switzerland. Tel: +4182355 90; Fax: +41 182353 75; E-mail: kasemir@eawag.ch.CC Jaeger is at Darmstadt University and at EAWAG. be separate activities. While we strongly support the first, we would doubt the second. A public discussion on climate-change policy without sufficient scientific input risks would be highly ineffective, while scientific modelling without sufficient input from public discussion risks focusing on irrelevant issues while ignoring questions of interest to the public.

If, however, rather than being separated, scientific modelling and public discussion processes could be integrated, a comprehensive assessment process with public participation might emerge. This would be a public discussion not only about "the many other possible justifications for acting", but also about scientific models and adequate ways to use them.

We think this strategy is especially promising for integrated environmental assessment (IEA). We define IEA broadly as procedures to arrive at an informed judgement on different courses of action with regard to environmental problems; the information required refers to physical, biological, and specifically human phenomena, including the relevant decision-making processes. In the climate-change context, the scope of IEA is an 'end-to-end' integration, from socio-economic causes of emissions, to climate change, and further to impacts on ecosystems and human welfare (Parson, 1994). Up to now, IEA has been pursued mainly as a modelling effort.

If climate research shows mutual construction with policy agendas, then this is inherited by the climaterelated part of IEA research. But IEA research differs from climate research proper in the scope of the exercise. IEA explicitly aims at integrating knowledge from different sources for the task of decision support. Because considerations of the policy community and the public is thus more openly present in IEA research than in climate research, IEA offers important opportunities for making mutual-construction processes conscious. Instead of ignoring or trying 
to suppress processes of mutual construction, they can be used to generate 'mutual support' of modelling efforts and public debate.

We want to stress that not only the climate-related part of IEA research involves 'mutual construction', but that a similar argument holds for the socioeconomic part of IEA-related research. Economic modelling relevant for IEA, for example, concerns costs and benefits of alternative $\mathrm{CO}_{2}$ (carbon dioxide) abatement strategies. Such modelling efforts usually involve the concept of economic equilibrium. It has been one of the important achievements of economic theory to demonstrate the existence of economic equilibria under well specified conditions.

A related result, however, has often not been considered sufficiently in this context. Linked to the proof of the existence of economic equilibria is the result that usually there is not only one equilibrium, but there exist multiple equilibria (Sonnenschein, 1974). We have argued that the existence of multiple equilibria casts severe doubts on the possibility of meaningful cost-benefit analysis concerning different alternative climate policies (Jaeger and Kasemir, 1996).

Why are many economic models built without acknowledging this possibility of multiple equilibria? A possible reason is that, without a unique equilibrium, models cannot answer questions like "what is the optimal climate policy strategy?". Even without impressive anecdotal evidence of mutual construction such as the one Shackley and Wynne obtained for climate research, it would appear that a similar mutual construction between the research agenda of economic modellers and the interest of decision-makers in optimisation models is quite likely. Disregarding the possibility of multiple equilibria in socioeconomic modelling might play a role parallel to, for instance, disregarding unlikely though possible catastrophic climate events and focusing only on best estimates in the IPCC (Intergovernmental Panel on Climate Change) scientific assessment of climate change (see the comment by Houghton, cited in Shackley and Wynne's paper, pages 226ff).
More adequate models might not yield unique optimal strategies. They would be more explanatory than predictive, and contain elements of irreducible uncertainty and surprise. Especially for this type of model it would hold true that the most productive way to use them would be as part of a wider public debate: models not yielding one recommended strategy would need additional input from human decisions, and they would also not prevent a productive discourse process by eliminating all but one option as legitimate. In effect, this would be more compatible with the workings of democracies, as democracy presupposes a variety of conflicting, yet legitimate interpretations. Integrated assessments could then be the output of environmental discourses informed by both scientific competence and democratic faimess (see also Renn et al, 1995).

In a planned European research project, named ULYSSES (Urban Lifestyles, Sustainability and Integrated Assessment) we therefore intend to conduct experiments on the interaction of monitored discourse groups with IEA models. The discourse group, which we call the IEA Jury, will be a microcosm of social learning, and will include the concerns of the intended users of IEA, emphasising the role of ordinary citizens. We are very pleased that Shackley and Wynne will take part in this effort, too, and hope that ULYSSES will yield results on how to deal productively with situations of mutual construction or mutual support connecting science and public policy.

\section{References}

C C Jaeger and B Kasemir (1996), "Climatic risks and rational actors", Global Environmental Change (in print).

E A Parson (1994), "Searching for integrated assessment: a preliminary investigation of methods and projects in the integrated assessment of climate changen", paper presented to the 3rd meeting of CIESIN-Harvard Commission on Global Environmental Change Information Policy, NASA Headquarters, 18 February 1994, Washington DC.

O Renn. T Webler and P Wiedemann (1995), Faimess and Competence in Citizen Participation: Evaluating Models for Environmental Discourse (Kluwer Academic Publisher, Dordrecht).

H Sonnenschein (1974), "Market excess demand functions", Econometrica, 40, pages 549-562. 